\title{
Fine Pitch and Low Temperature Bonding Using Solder Bumps and the Assessment of Solder Joint Reliability
}

\author{
Seung-Min Chung and Young-Ho Kim* \\ Division of Materials Science \& Engineering, Hanyang University, Seoul, 133-791, Korea
}

We developed a bonding at low temperature using fine pitch Sn and In bumps at $120^{\circ} \mathrm{C}$, and studied the reliability of the fine pitch In-Sn solder joints. The $30 \mu \mathrm{m}$ pitch $\mathrm{Sn}$ and In bumps were joined together without flux at $120^{\circ} \mathrm{C}$ for 2 minutes under $70.2 \mathrm{MPa}$. A non conductive adhesive (NCA) was applied during solder joining. Thermal cycling test $\left(0^{\circ} \mathrm{C}-100^{\circ} \mathrm{C}, 2\right.$ cycles $\left./ \mathrm{h}\right)$ of up to 2000 cycles and 1000 -h temperature and humidity test $\left(40^{\circ} \mathrm{C} / 95 \%\right)$ were carried out to evaluate the reliability of the solder joints. The bondability was evaluated by measuring the contact resistance $\left(\mathrm{R}_{\mathrm{c}}\right)$ of the joints through the four point probe method. The solder joints were characterized by scanning electron microscopy with energy dispersive X-ray spectroscopy. Joints between the In and Sn bumps were successfully made at $120^{\circ} \mathrm{C}$. The average contact resistance of the In/Sn solder joints was $10-14 \mathrm{~m} \Omega$ before thermal cycling. Without the NCA, the solder joints between the Si chip and glass substrate failed electrically in the early stages of the thermal cycling test. The failure in the solder joint during thermal cycling was attributed to the thermal expansion mismatch between the Si chip and glass substrate. In contrast, no electrical failures were observed in the joints with applied NCA even after 2000 cycles. The flip chip joints with applied NCA were stable up to 1000 hours in the temperature and humidity test. [doi: $10.2320 /$ matertrans.48.37]

(Received October 12, 2006; Accepted November 8, 2006; Published December 25, 2006)

Keywords: COG (chip on glass) bonding, NCA (non conductive adhesive) bonding, Flip chip bonding, Reliability test

\section{Introduction}

Electronic devices that contain heat-sensitive components require a low temperature packaging. Liquid Crystal Display (LCD) and image sensors, for example, should be processed at low temperature since the polymer materials may be degraded at high temperature. ${ }^{1)}$ A low temperature bonding technique was developed using a chromium-tin-indium-gold multilayer composite, ${ }^{2)}$ which is fluxless with a relatively low bonding temperature of $140^{\circ} \mathrm{C}$. This technique has been applied to the Bi-Sn and In-Ag systems. ${ }^{3)}$ While effective, the above technique requires the complex multi metal layer deposition.

With the continued miniaturization of electronic components and their increasing functionality, electronics are rapidly switching towards fine pitch devices and thus the demand for these various devices has remarkably increased in recent years. ${ }^{4,5)}$ The electronic devices must achieve high speed requirements and maintain excellent performance along with a higher $\mathrm{I} / \mathrm{O}$ count. The flip chip technology is a viable approach that meets fine pitch and high performance requirements. A low temperature process is preferred in flip chip techniques because it minimizes the residual stresses generated by the thermal mismatch and prevents breakage or fatigue inside the device. We developed a low temperature bonding technique using In and Sn bumps. ${ }^{6}$ ) When the In and Sn solders are in contact under pressure, solder joints are formed by interdiffusion between the In and Sn solders. The interdiffusion between the In and $\mathrm{Sn}$ atoms leads to the formation of intermediate phases and the melting temperature decreases to the eutectic temperature shown in Fig. 1. ${ }^{7)}$ Metallurgical bonding due to the melting of the intermixed phases is possible below the melting point of either pure In or $\mathrm{Sn}$. Thus, solder joining is possible at temperatures lower than $150^{\circ} \mathrm{C}$. In this study, we investigated low temperature

*Corresponding author, E-mail: kimyh@hanyang.ac.kr

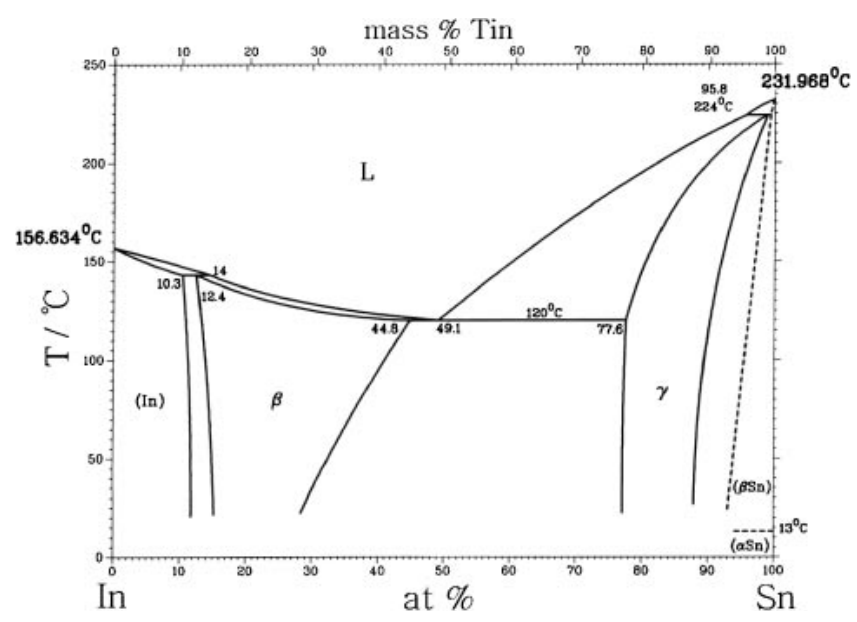

Fig. 1 In-Sn phase diagram. ${ }^{7)}$

and ultra fine pitch fluxless bonding using In and Sn solder bumps. The possibility of solder joint formation at $120^{\circ} \mathrm{C}$ was investigated with $30 \mu \mathrm{m}$ pitch $\mathrm{Sn}$ and In bumps. Reliability tests were carried out on these fine pitch solder joints. We also applied a non conductive adhesive (NCA) to the solder joints to improve reliability.

\section{Experimental Procedure}

$\mathrm{Au}(0.05 \mu \mathrm{m}) / \mathrm{Cu}(1 \mu \mathrm{m}) / \mathrm{Ti}(0.05 \mu \mathrm{m})$ thin films were deposited to form metal pads using DC magnetron sputtering on the Si wafer and glass substrate. The metal patterns for under bump metallurgy (UBM) and interconnection were fabricated through a photolithographic process and wet chemical etching. Solder bumps $(20 \mu \mathrm{m} \times 45 \mu \mathrm{m})$ were formed on the metal pads using evaporation and the lift-off methods. The Sn solder bumps were formed on the Si wafer chips, and the In solder bumps were formed on the glass substrates. 

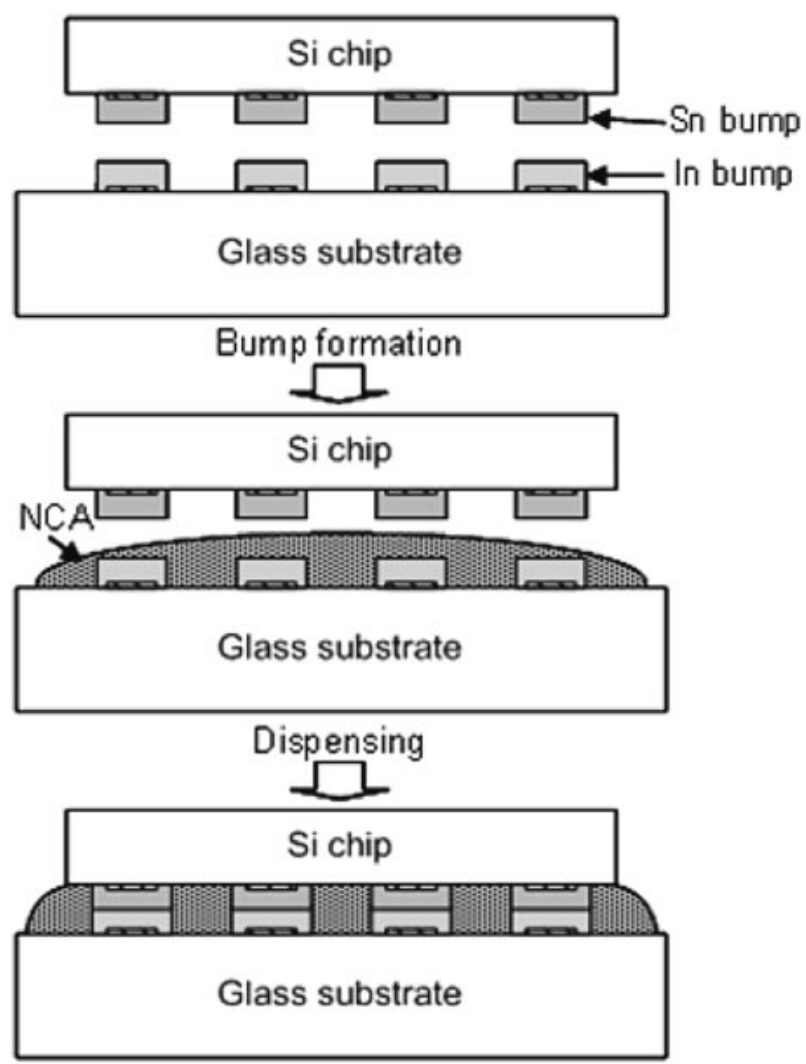

Flip chip bonding \& curing

Fig. 2 Schematic view of solder joint formation.

A NCA which was composed of liquid epoxy resin and fillers (obtained from Emersion \& Cuming Co. Ltd.) was dispensed on glass substrate on which the In bumps were formed using the injector and then the Sn bumps on the $\mathrm{Si}$ chip were aligned to the corresponding In bumps on the glass substrate using a flip chip bonder. The In bumps and Sn bumps were joined at $120^{\circ} \mathrm{C}$ for $2 \mathrm{~min}$ under a pressure of $70.2 \mathrm{MPa}$ which is divided the pressure $(\mathrm{N})$ by the total area of the entire bumps. Figure 2 details the process flow. Solder joints were formed between the Si chip and Si substrate instead of a glass substrate to investigate the effect of differences in thermal expansion. The contact resistance was measured using the four-point probe method. Figure 3(a) represents a sketch of the test chip for the electrical tests and Fig. 3(b) shows the circuitry for contact resistance. To evaluate the bondability of the solder joints, the contact resistance of each bump was measured. To evaluate their reliability, thermal cycling test $\left(0^{\circ} \mathrm{C}-100^{\circ} \mathrm{C}, 2\right.$ cycles/h) up to 2000 cycles and temperature and humidity test $\left(40^{\circ} \mathrm{C} /\right.$ $95 \%, 1000 \mathrm{~h}$ ) were carried out. The initial contact resistance was measured using the four-point probe method and after each time point; the contact resistance was measured at room temperature upon completion of the thermal cycling and temperature humidity tests. The failure criterion was defined as $500 \mathrm{~m} \Omega$; The value larger than $500 \mathrm{~m} \Omega$ was regarded as a failed one. The failure rate means the ratio of the number of the failed solder joints to that of the total solder joints. To analyze the failure mechanism, the solder joints were crosssectioned and characterized by scanning electron microscopy (SEM).

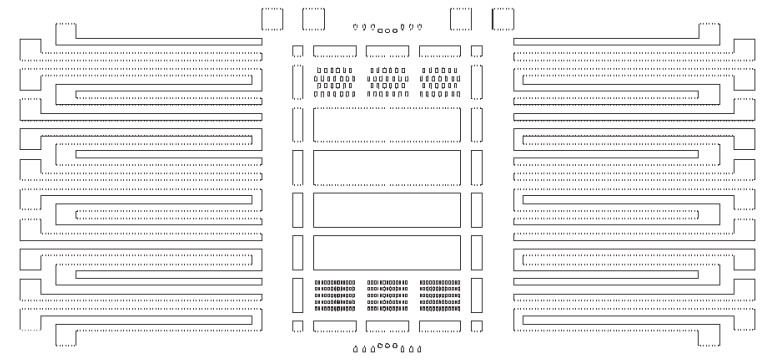

(a)

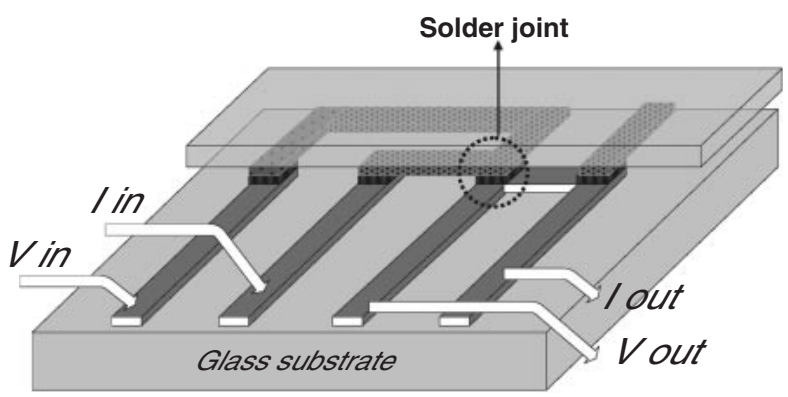

(b)

Fig. 3 Schematic diagram of (a) the test chip design and (b) the circuitry for the contact resistance measurements.

\section{Results}

\subsection{Bump-to-bump bonding using $30 \mu \mathrm{m}$ pitch $\mathrm{In}$ and $\mathrm{Sn}$ bumps}

Figure 4 contains SEM images that show the In and Sn bumps of a $30 \mu \mathrm{m}$ pitch. The solder bumps were fabricated using an evaporation method and lift-off. The thickness of the In and Sn bumps was $5 \mu \mathrm{m}$ and $7.5 \mu \mathrm{m}$, respectively. They were formed uniformly on the $\mathrm{Au} / \mathrm{Cu} / \mathrm{Ti}$ metal pads. Figure 5 shows SEM image of the $\mathrm{Au} / \mathrm{Cu} / \mathrm{Ti}$ interconnection lines and the In bumps formed on the interconnection lines for electrical testing. Figure 6 shows an SEM image of the In/Sn solder joints assembled at $120^{\circ} \mathrm{C}$. The bonding was successfully made through the In/Sn solder joints formed between the Si chip and glass substrate without a flux. In Fig. 6(b), the In bump on the glass substrate deformed more than the Sn bump on the Si chip after bonding because In is softer than $\mathrm{Sn}^{8)}$

The average contact resistance of the eutectic In/Sn solder joints with and without NCA before thermal cycling are shown in Table 1. The average contact resistance values of all solder joints were measured between 10 and $14 \mathrm{~m} \Omega$ and no solder joints failed electrically. The contact resistance without NCA is slightly smaller than that with NCA since NCA was not trapped in the solder joint fabricated without NCA. All joints had a very low contact resistance value independent of NCA applications. The substrate type did not affect the bondability or the contact resistance of the solder joints. The contact resistances of the solder joints fabricated using the bump to bump bonding method in this experiment were much lower than that of the COG bonding using the conventional ACF method which has a few hundred $\mathrm{m} \Omega$ per bump. ${ }^{9)}$ SEM observations and contact measurement data demonstrate that the 30- $\mu \mathrm{m}$ pitch solder bumps were joined successfully both with and without the NCA at $120^{\circ} \mathrm{C}$. 


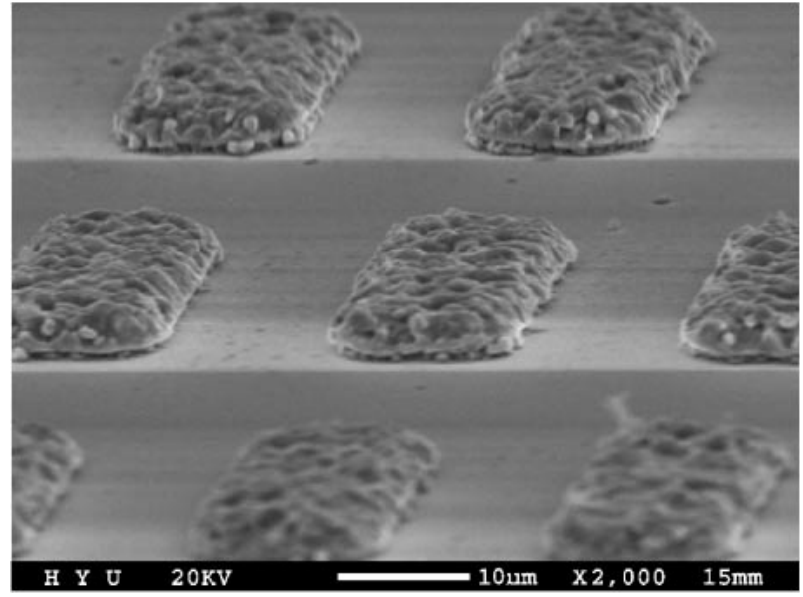

(a)

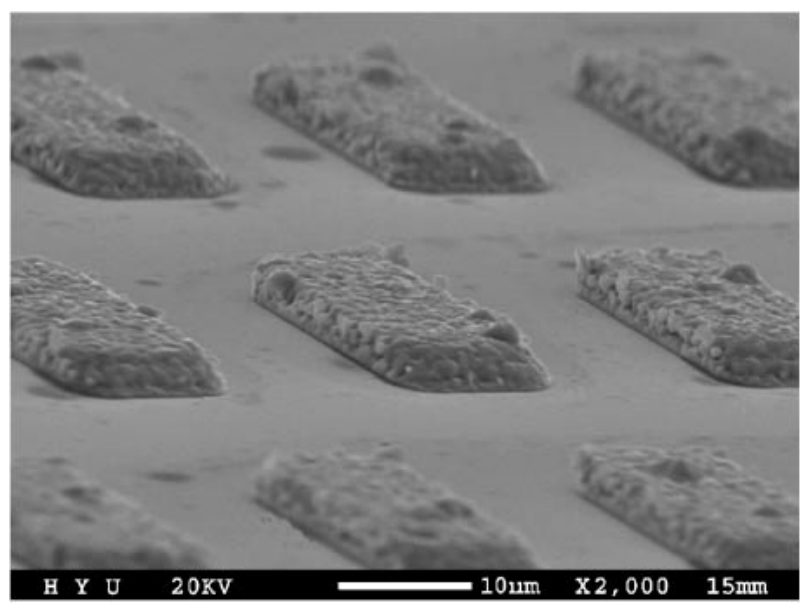

(b)

Fig. 4 SEM images showing (a) In bumps (b) Sn bumps.

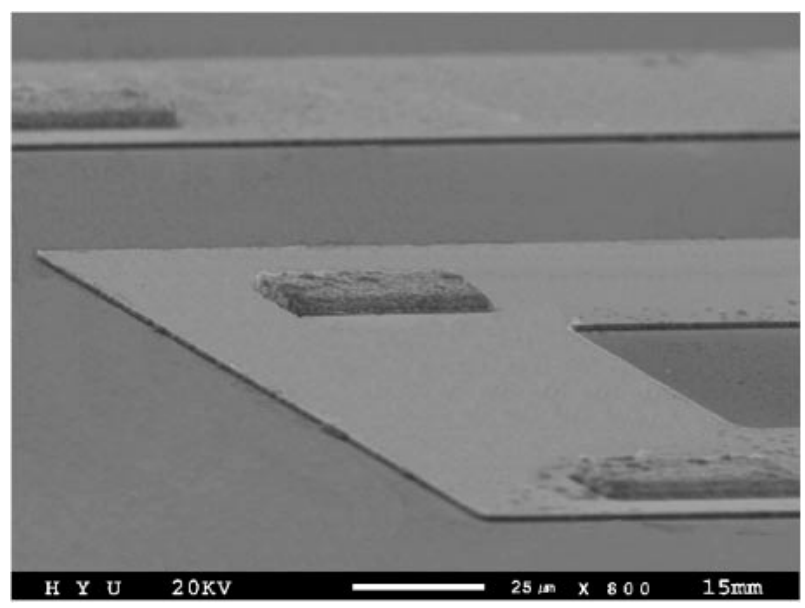

Fig. 5 SEM image showing the metal lines and In bumps.

\subsection{Thermal cycling test results}

The average contact resistance of the In/Sn solder joints after thermal cycling test of up to 2000 cycles are shown in Fig. 7. The contact resistance of the solder joints bonded between the Si chip and the glass substrate without the NCA

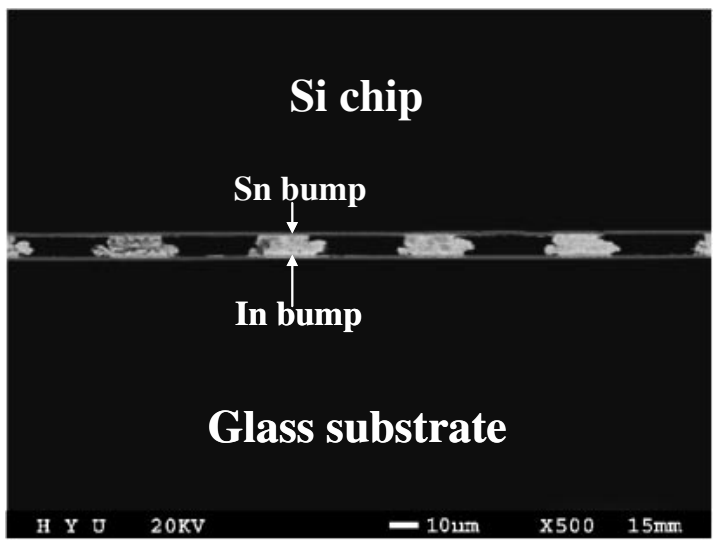

(a)

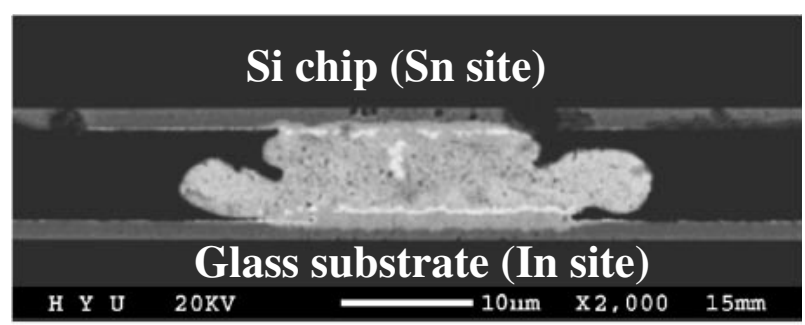

(b)

Fig. 6 (a) A cross-section SEM image of the 30- $\mu \mathrm{m}$ pitch $\mathrm{In} / \mathrm{Sn}$ solder joint (b) a magnified image of a solder joint in Fig. 6(a).

Table 1 The average contact resistance and deviation before thermal cycling tests with and without NCA.

\begin{tabular}{lll}
\hline & \multicolumn{2}{c}{ Resistance [Deviation] $(\mathrm{m} \Omega)$} \\
\cline { 2 - 3 } & $\mathrm{NCA}$ & No NCA \\
\hline Si chip to glass substrate & $14.0[2.9]$ & $10.2[1.7]$ \\
Si chip to Si substrate & $13.5[2.5]$ & $10.5[2.2]$ \\
\hline
\end{tabular}

increased quickly with increased thermal cycling and failed completely after 750 cycles. The contact resistance of the solder joints bonded between Si chip and Si substrate without the NCA increased with increasing thermal cycles and reached about $74 \mathrm{~m} \Omega$ after 2000 cycles. All joints using the NCA had contact resistance values under $25 \mathrm{~m} \Omega$ even after 2000 cycles regardless of the substrate type. The contact resistance of the solder joints with the applied NCA increased slightly after 250 cycles and remained constant with respect to further thermal aging. The change of the contact resistance value with respect to thermal cycle in the solder joints that had NCA applied had a trend similar to the glass and Si substrates. Figure 8 shows the failure rate of the solder joints formed between the Si chip and Si substrate and between the Si chip and glass substrate without the NCA. The failure rate of the solder joints between the Si chip and glass substrate increased with thermal cycling and reached $100 \%$ after 750 cycles, but the solder joints between the $\mathrm{Si}$ chip and $\mathrm{Si}$ substrate survived up to 2000 cycles. This data suggests that reliability would be a serious problem if the NCA was not applied during the bonding between the Si chip and glass substrate. 


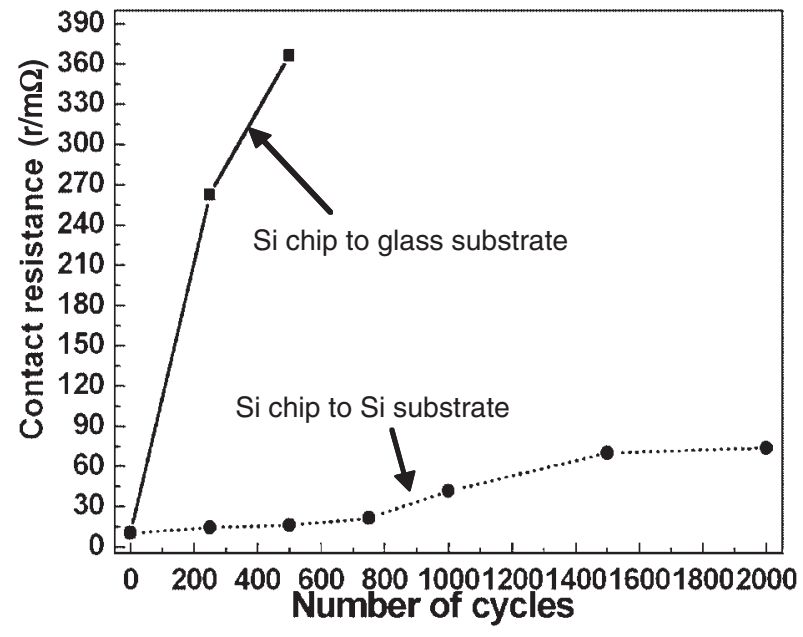

(a)

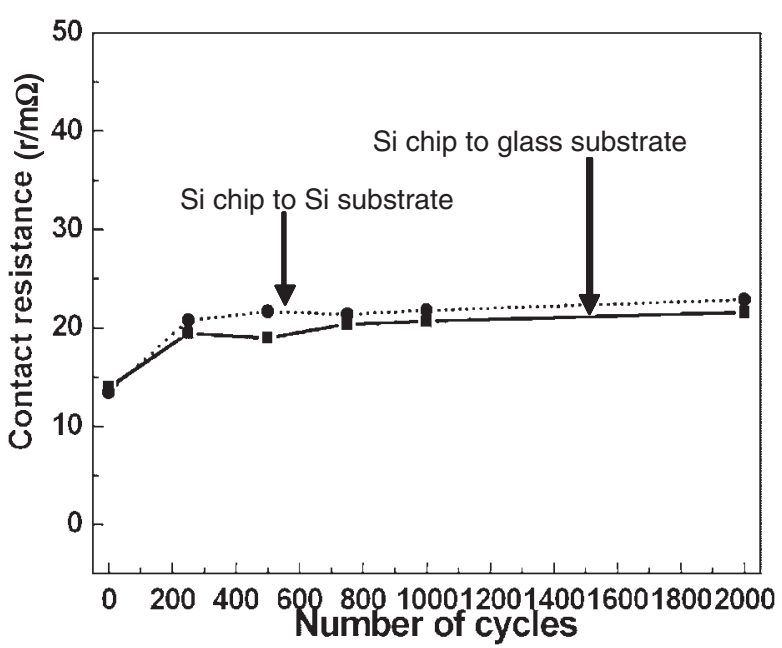

(b)

Fig. 7 Average contact resistance of the adhesive flip chip interconnects during a $0^{\circ} \mathrm{C}-100^{\circ} \mathrm{C}$ thermal cycling test, (a) without the $\mathrm{NCA}$, (b) with the NCA.

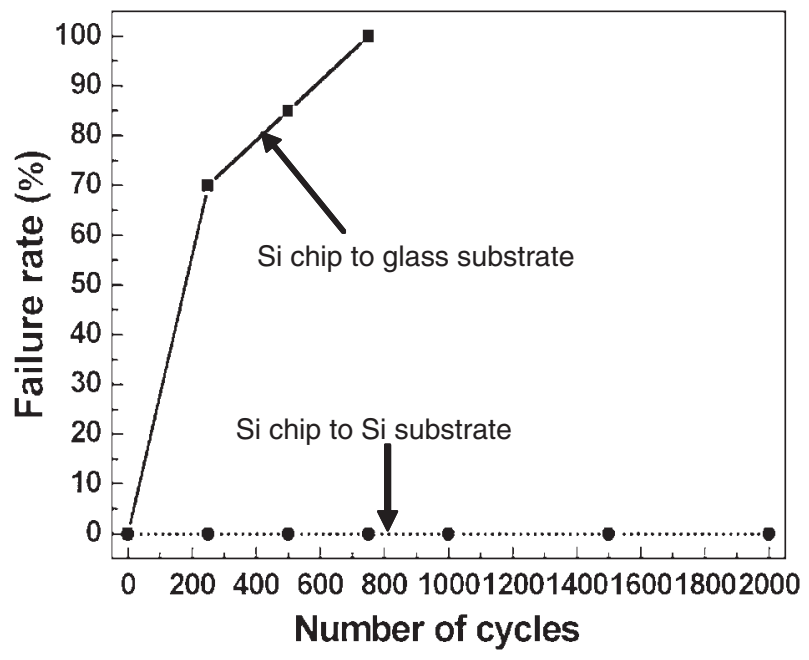

Fig. 8 Failure rate of the adhesive flip chip interconnects during the $0^{\circ} \mathrm{C}-$ $100^{\circ} \mathrm{C}$ thermal cycling test without the NCA.

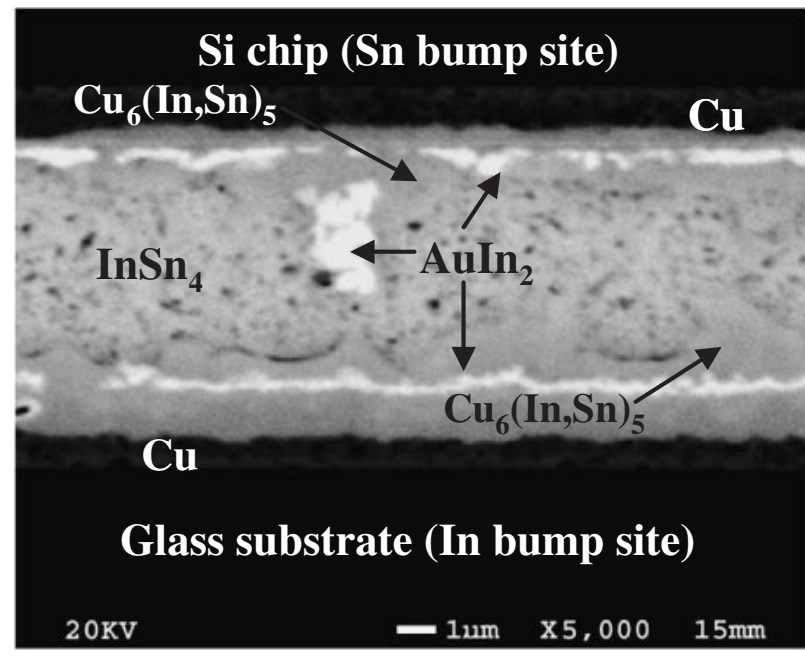

Fig. 9 Backscattered electron image of the In/Sn solder joint after bonding.

\subsection{Microstructural characteristics before and after the thermal cycling tests}

Figure 9 contains the back-scattered electron (BSE) image of the cross-sections of the solder joint that was bonded at $120^{\circ} \mathrm{C}$ for 2 minutes with the NCA. The microstructure was clearly observed using the BSE image and $\mathrm{EDX}$. $\mathrm{Cu}_{6}(\mathrm{Sn}$, In) $)_{5}, \mathrm{AuIn}_{2}$ and $\mathrm{InSn}_{4}$ intermetallic compounds (IMCs) were observed in the solder joints. Most In and Sn phases transformed to $\mathrm{InSn}_{4}$ IMC and only fractions of In and $\mathrm{Sn}$ phases might remain as a island form in the solder joint after bonding, ${ }^{9)}$ but it was very difficult to find them. $\mathrm{InSn}_{4}$ formed in the center of the solder joint, and $\mathrm{Cu}_{6}(\mathrm{Sn}, \mathrm{In})_{5}$ formed at both $\mathrm{Cu}$ interfaces. The intermixing of the $\mathrm{Sn}$ and $\mathrm{In}$ in the solder joints indicated that interdiffusion occurred across the $\mathrm{In} / \mathrm{Sn}$ interface during bonding. The Au of the UBM diffused completely into the solder to form $\mathrm{AuIn}_{2}$. AuIn 2 IMCs (the bright regions in Fig. 9) were formed as a layer along the $\mathrm{Cu}_{6}(\mathrm{Sn}, \mathrm{In})_{5} \mathrm{IMCs}$ and as an island-type in the solder center.

Figure 10 shows the BSE images of the cross-sections of the solder joints bonded using the NCA after thermal cycling. Dimensional changes and cracks in the solder joints were not found in these SEM images. One micrometer-thick Cu UBM on the chip and glass substrate were completely transformed into $\mathrm{Cu}_{6}(\mathrm{Sn}, \mathrm{In})_{5}$ after the thermal cycling test. Island-type $\mathrm{AuIn}_{2}$ IMCs were also observed. The $\mathrm{AuIn}_{2}$ remained stable at the $\mathrm{Cu}_{6}(\mathrm{Sn}, \mathrm{In})_{5}$ interface and in the center region of the solder joint even after the thermal cycling test. The magnified images of the solder joints after the thermal cycling tests can be seen in Fig. 11. AuIn 2 was not uniformly distributed in the solder joint. The large size of $\mathrm{AuIn}_{2}$ phase was observed in some regions. But the total fraction of $\mathrm{AuIn}_{2}$ phase in the solder joint does not seem to be increased with thermal cycling, as the low magnification pictures shown in Fig. 10. Fig. 11(a), which depicts the secondary electron (SE) image of the solder joint before thermal cycling, revealed $\mathrm{Cu}_{6}(\mathrm{Sn}$, In) $)_{5}$ in the $\mathrm{Cu}$ interface and $\mathrm{InSn}_{4}$ in the center region of the solder joint, which was similar to the BSE image shown in Fig. 9. As the number of thermal cycles increased, the $\mathrm{InSn}_{4}$ phase decreased and remained as an island-type phase after 500 cycles. After 750 cycles, the $\mathrm{InSn}_{4}$ phase had nearly 


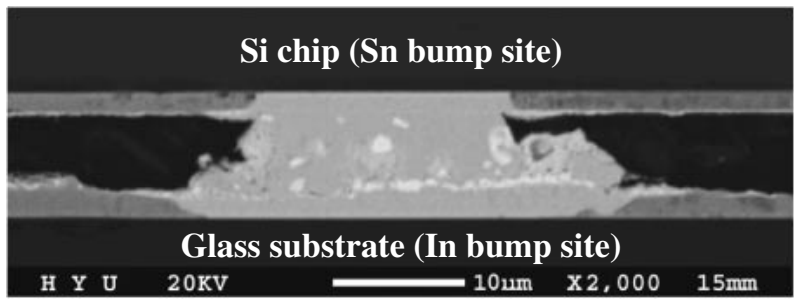

(a) 250 cycles

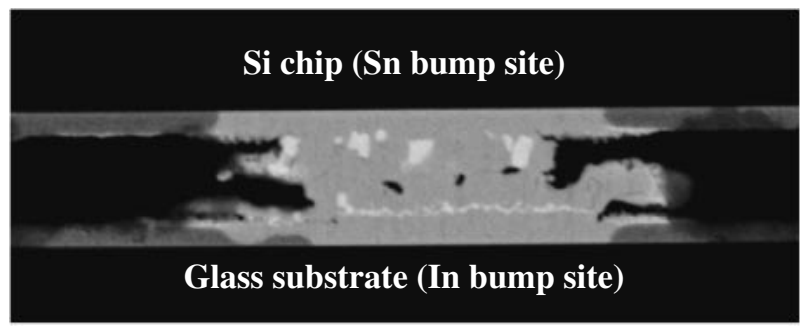

(b) 2000 cycles

Fig. 10 Cross-sectional BS image of the In/Sn solder joint with the NCA after the thermal cycling test (a) 250 cycles (b) 2000 cycles.

disappeared from the solder joint. In contrast, the $\mathrm{Cu}_{6}$ (In, $\mathrm{Sn})_{5}$ layer grew from the copper interfaces during the thermal cycling test. The $\mathrm{Cu}_{6}(\mathrm{In}, \mathrm{Sn})_{5}$ layers of both interfaces merged together after 250 cycles, and after 750 cycles most of the solder joints consisted of $\mathrm{Cu}_{6}(\mathrm{In}, \mathrm{Sn})_{5}$. The distribution of the $\mathrm{AuIn}_{2}$ phase did not change with respect to thermal cycling, which is consistent with the results obtained earlier (Fig. 10).

The solder joints fabricated without the NCA are shown in Fig. 12. The solder joint consisted of $\mathrm{Cu}_{6}(\mathrm{Sn}, \mathrm{In})_{5}, \mathrm{AuIn}_{2}$, and $\mathrm{InSn}_{4}$. The microstructure was similar to that of the solder joint bonded with the NCA. Cracks formed and propagated in the $\mathrm{Cu}_{6}(\mathrm{Sn}, \mathrm{In})_{5}$ layer in the solder joint. Cracks initiated at the surface of the solder joints and grew into the solder joints with repeated thermal cycling. The cracks were observed near the Si chip side, near the glass side, or both in the solder joints. Figure 12(c) shows that the Si chip was separated from the glass substrate as a result of cracking in the solder joint after 750 cycles.

\subsection{Temperature \& humidity ( $\mathrm{T} \& \mathrm{H})$ test results}

The failure rate and the contact resistance of the solder joint with and without NCA during conditions of $40^{\circ} \mathrm{C} / 95 \%$ relative humidity for 1000 hours are shown in the Fig. 13. In the solder joint formed without the NCA, the failure rate and the contact resistance increased with respect to storage time. The contact resistance of the solder joints with NCA applied increased slightly after $600 \mathrm{~h}$, but the failure rate remained at $0 \%$ throughout the test.

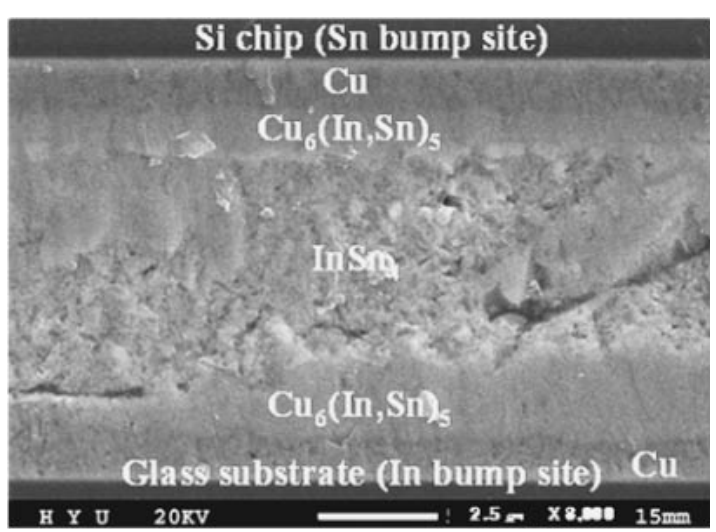

(a) 0 cycle

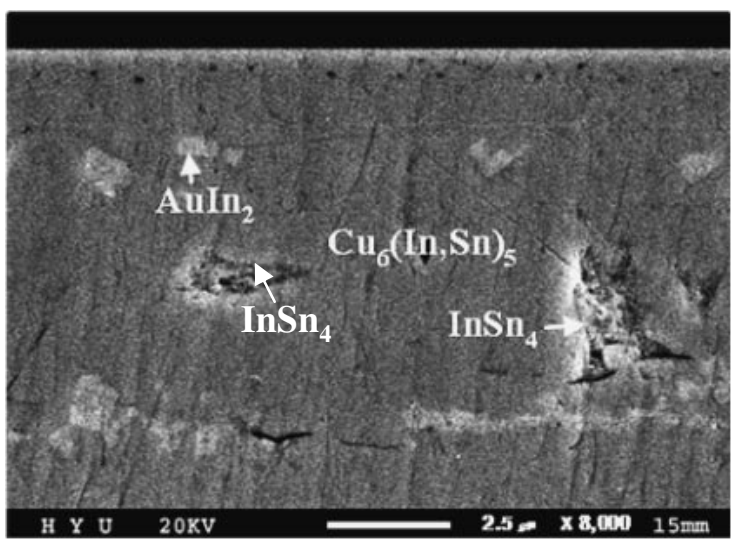

(c) 500 cycles

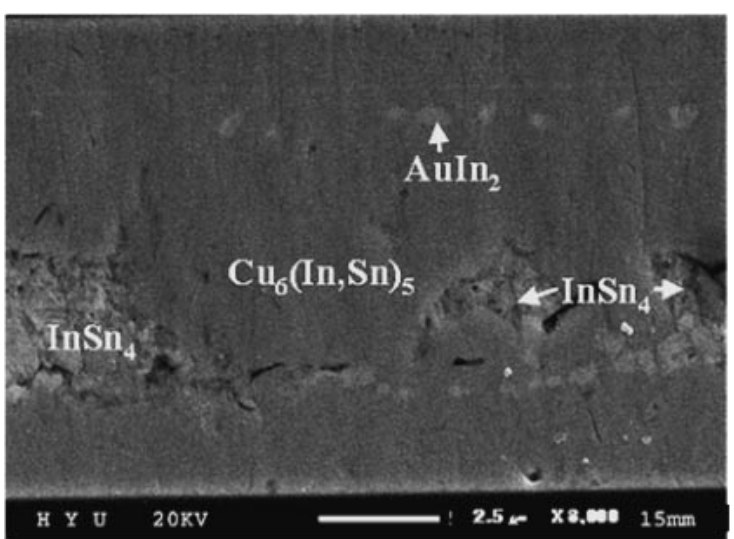

(b) 250 cycles

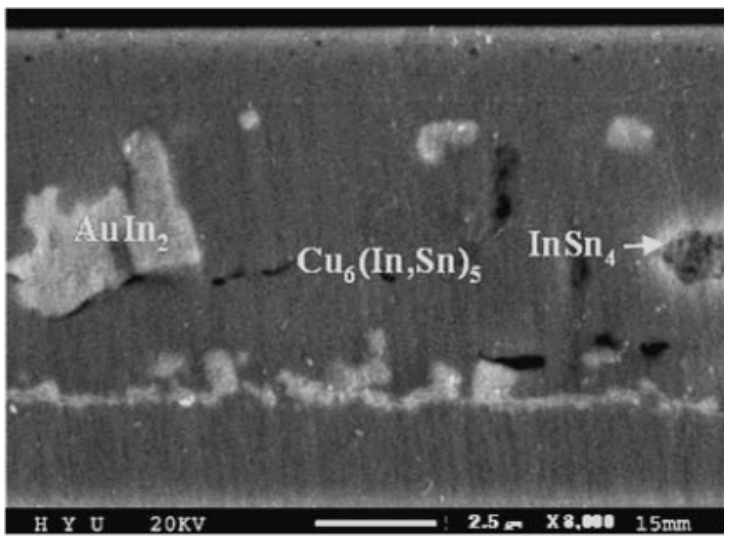

(d) 750 cycles

Fig. 11 Cross-sectional SEM image of the In/Sn solder joint before and after the cycling test with the NCA. 


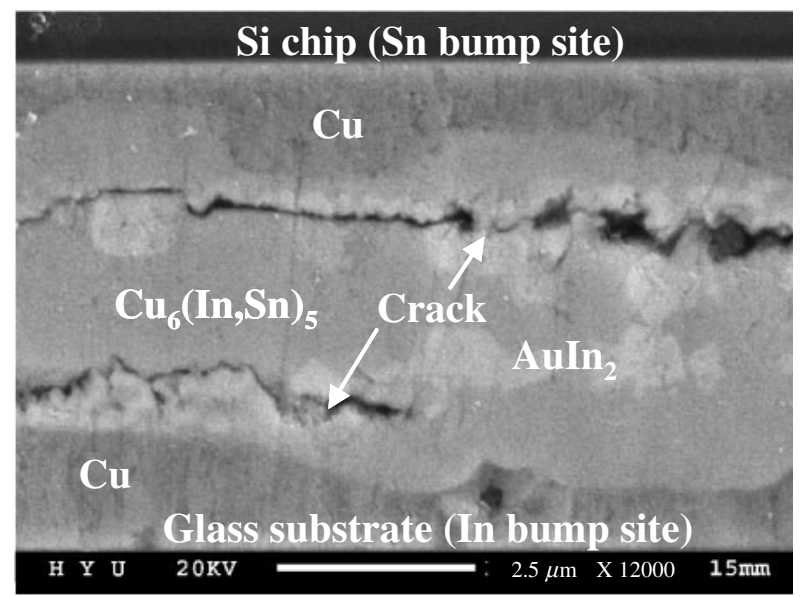

(a) 250 cycles

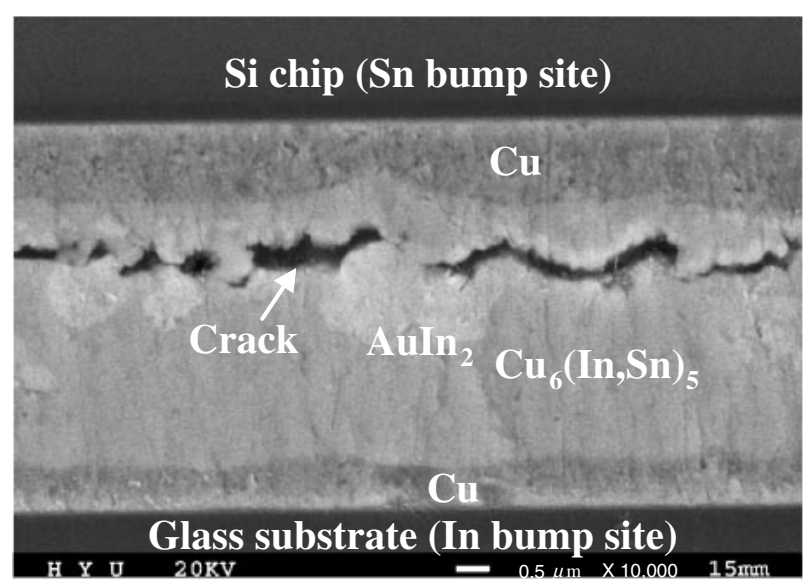

(b) 500 cycles

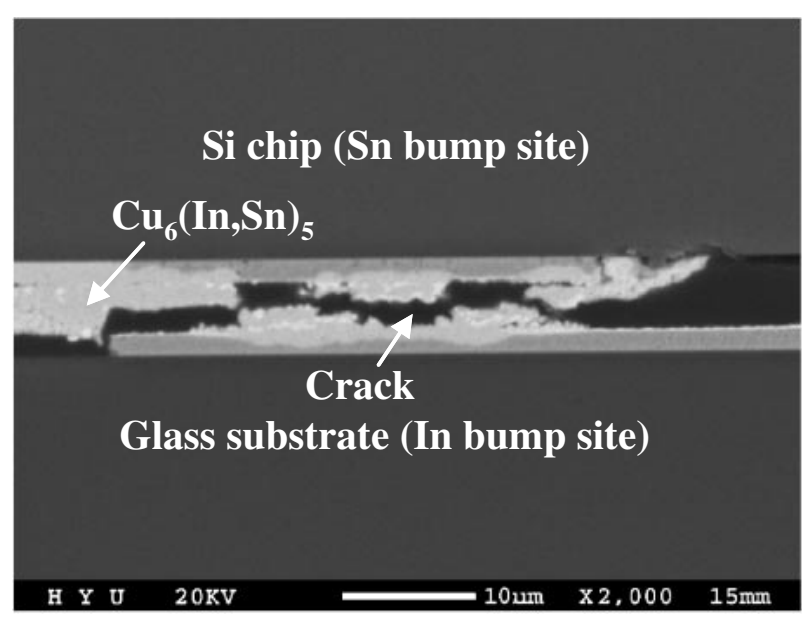

(c) 750 cycles

Fig. 12 Cross-sectional SEM image of a crack in the In/Sn solder joint without the NCA: (a) After 250 cycling test (b) After 500 cycling test (c) After 750 cycling test.

\section{Discussion}

Our results showed that the $30-\mu \mathrm{m}$ pitch In and Sn solder bumps were joined successfully at $120^{\circ} \mathrm{C}$ without a flux. During the bonding process, the oxide layers on the solder

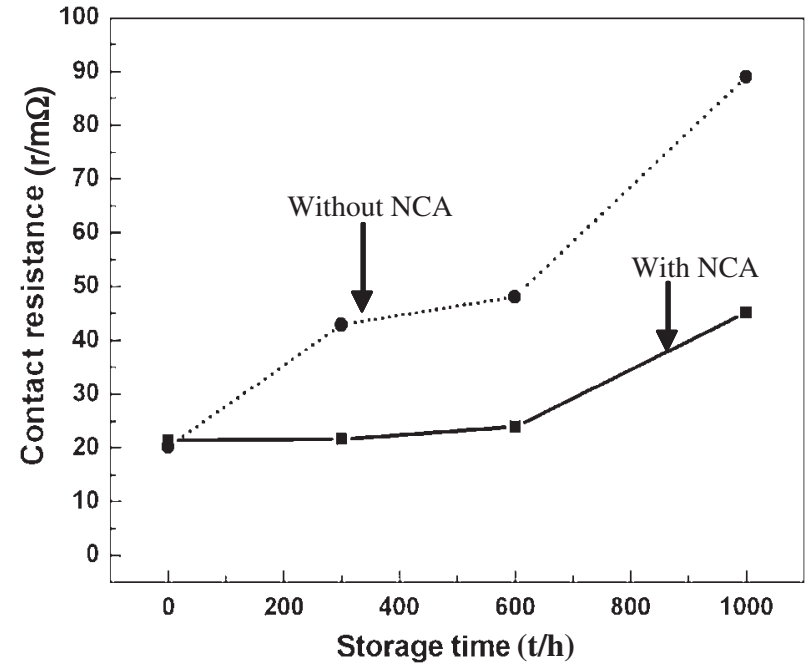

(a)

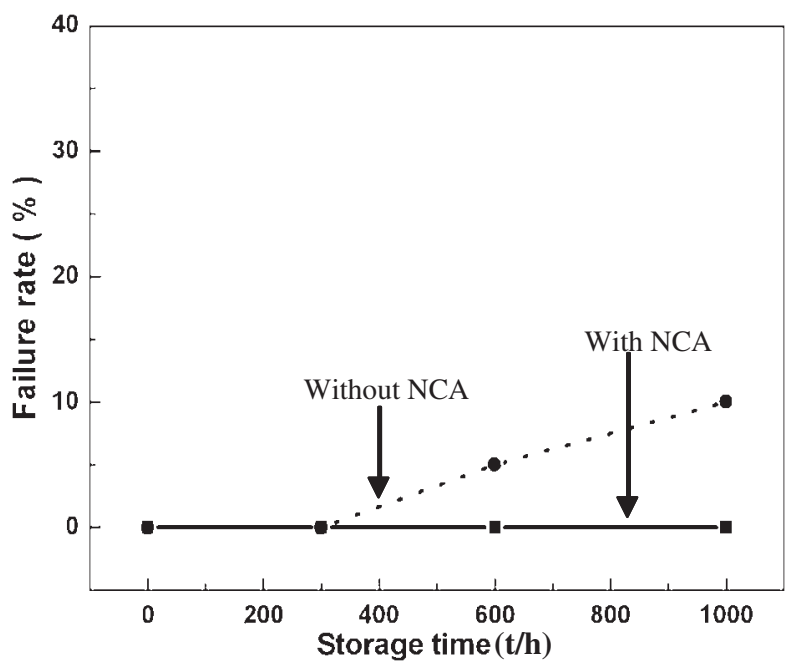

(b)

Fig. 13 Failure rate and contact resistance of the solder joints via temperature humidity tests with and without the NCA (a) Average contact resistance (b) Failure rate.

surfaces prevent the In and Sn atoms from diffusing into each other, making it difficult to obtain adequate bonding. ${ }^{10)}$ Therefore, a flux is normally used during the bonding process to remove the oxide layers. Since the oxide layer can be broken under high bonding pressures, interdiffusion is possible between the $\mathrm{Sn}$ and In solders without a flux. ${ }^{9)}$ The formation of $\mathrm{InSn}_{4}$ in the solder joint proved that active solid-state interdiffusion occurred across the interface between the In and Sn bumps. As bonding continued, an intermixed layer would be formed at the interface of the In and Sn bumps. Thus, the In bump and Sn bumps can bond under temperatures below their respective melting points, namely $157^{\circ} \mathrm{C}$ for In and $232^{\circ} \mathrm{C}$ for $\mathrm{Sn}$. All of the joints had a low contact resistance value and there were no failed joints because interdiffusion occurred irrespective of the application of NCA and regardless of substrate type.

The solder joints between the Si chip and glass substrate failed in the specimens bonded without NCA, but those between the Si chip and Si substrate survived after thermal 
cycling. These results suggest that the failure was due to the thermal expansion mismatch between the $\mathrm{Si}$ and glass during the thermal cycling. The CTE of the silicon wafer is $2.7 \mathrm{ppm},{ }^{11)}$ and the CTE of the glass substrate used in this experiment is measured at $10.2 \mathrm{ppm} .{ }^{12)}$ During the thermal cycling test, especially during the temperature dwelling period, the glass substrate expanded more than the Si wafer chip, and a thermal stress was generated. During the thermal cycling test, the $\mathrm{Cu}_{6}(\mathrm{Sn} \text {, In })_{5}$ IMCs grew from the $\mathrm{Cu}$ interface in the solder joints. The thickness of the $\mathrm{Cu}_{6}(\mathrm{Sn}$, In $)_{5}$ increased with respect to increasing cycle number. As the $\mathrm{Cu}_{6}(\mathrm{Sn}, \mathrm{In})_{5}$ comprised the major phase in the solder joint, the solder joint became weaker since $\mathrm{Cu}_{6}(\mathrm{Sn}, \mathrm{In})_{5}$ was harder than $\mathrm{InSn}_{4} .{ }^{9)}$ Cracks formed in the brittle $\mathrm{Cu}_{6}(\mathrm{Sn}, \mathrm{In})_{5}$ IMC due to thermal stress. Cracks were observed in the $\mathrm{Cu}_{6}(\mathrm{Sn}, \mathrm{In})_{5}$ layer in the solder joint. The failed bumps and cracks did not exist in the solder joints between the Si chip and $\mathrm{Si}$ substrate. These results indicated that the cracks formed due to the CTE mismatch between the Si and glass. In the specimen bonded with NCA, the NCA redistributed the stress and strains from the CTE mismatch and mechanical shock over the entire joint area by tightly adhering to the chip, solder joints, and substrate. As a result, crack initiation and growth in the solder joint was either prevented or drastically reduced.

It was also noticed that the contact resistance slightly increased from 0 to 250 cycles [Fig. 7(b)]. After 250 thermal cycles, $\mathrm{Cu}$ UBM was completely converted to $\mathrm{Cu}_{6}(\mathrm{In}, \mathrm{Sn})_{5}$ IMC which has a high resistivity $(19.9 \mu \Omega-\mathrm{cm}) .{ }^{13)}$ A slight increase in the resistance was related to microstructural changes in the solder joints.

The contact resistance of the solder joints bonded between the $\mathrm{Si}$ chip and glass substrates without NCA slowly increased with each test during $\mathrm{T} \& \mathrm{H}$ test and the solder joints began to fail after 250 hours. The increase of the contact resistance and failure rate in the solder joints without the NCA were likely due to corrosion of the interconnection lines and solder joints which were exposed to moisture during $\mathrm{T} \& \mathrm{H}$ test. ${ }^{14)}$ The NCA suppressed the penetration of moisture and the contact resistance did not increase rapidly in the solder joints when the NCA was applied. The secondary benefit from NCA is partial protection against moisture ingress, and other forms of contamination. Consequently, the quality and reliability of the NCA material itself will greatly impact the component reliability. ${ }^{15)}$ The NCA is one of key materials in providing protection to the solder interconnect, improving mechanical integrity to the package and thereby the overall reliability of the package significantly.

\section{Conclusions}

In this paper, we developed a new, low temperature, fluxless bonding technique using a NCA. The reliability of the NCA-applied flip-chip joints was investigated. Without the NCA, all joints failed during the thermal cycling test. In contrast, no electrical failures were observed in the joints applied with NCA during the test. Cracks propagated through the $\mathrm{Cu}_{6}(\mathrm{Sn}, \mathrm{In})_{5}$ layer in the solder joint. The thermal mismatch between the Si chip and the glass substrate was the main source of cracking during the thermal cycling test. The NCA improved stress distribution in the solder joints during thermal cycling and reduced the penetration of moisture during the temperature and humidity test, which markedly increased their reliability. It is believed that the In/Sn joints with NCA can be applied in low temperature, fine pitch bonding.

\section{Acknolegement}

This research was supported by a grant (F0004121-200622) from the Information Display $R \& D$ Center, one of the 21st Century Frontier R\&D Program funded by the Ministry of Commerce, Industry and Energy of the Korean Government.

\section{REFERENCES}

1) H. Kristiansen and J. Liu: IEEE Tran. Comp. Packag. Manufact. Technol. A 21 (1998) 208-214.

2) C. C. Lee and S. Choe: Mater. Sci. Eng. (2002) 45-50.

3) U.-B. Kang and Y.-H. Kim: IEEE Trans. Compo. \& Packag. Techno. 27 (2004) 253-258.

4) U.-B. Kang and Y.-H. Kim: Int'1 Sympo. On Electro. Mater. \& Packag. (2001) 129-134.

5) C. C. Lee and Y.-C. Chen: Thin Solid Film. 286 (1996) 213-218.

6) M. S. Lee, U. B. Kang and Y.-H. Kim: Inter. Symp. Electron. Mater. Packag. (2003) 93-97.

7) H. Okamoto: Binary alloy phase diagrams T. B. Massalski (Ed.), (ASM International, Metals Park, 1999) pp. 2295-2296.

8) E. A. Brandes and G. B. Brook: Smithells Metals Reference Book (Butterworth-Heinemann, Boston 1998).

9) S.-H. Lee and Y.-H. Kim: Key Engineering Materials 297-300 (2005) 857-862.

10) Y. C. Chen and C. C. Lee: Thin Solid Films 283 (1996) 243-246.

11) Y. Okada and Y. Tokumaru: J. Appl. Phys. 56 (1984) 314-320.

12) S.-M. Chung: Master's Thesis (Hanyang University, Seoul 2006) 68.

13) J.-H. Choi, K.-Y. Lee, S.-W. Jun, Y.-H. Kim and T.-S. Oh: Mater. Transac. 46 (2005) 1042-1046.

14) M. Datta, T. Osaka and J. W. Schultze: Microelectronic Packaging (CRC Press, New York, 2000) pp. 196.

15) M. Datta, T. Osaka and J. W. Schultze: Microelectronic Packaging (CRC Press, New York, 2000) pp. 268-269. 